\title{
Bioremediation of $\mathrm{Cu}(\mathrm{II})$ contaminated water by Saccharum officinarum: effect of oxalic acid modification on equilibrium, kinetic and thermodynamic parameters
}

Abideen Idowu Adeogun ${ }^{1 *} \mathbb{D}$, Mopelola Abidemi Idowu' ${ }^{1}$ Kayode Olubunmi Akiode ${ }^{1}$ and Sikiru Akiyeye Ahmed ${ }^{2}$

\begin{abstract}
Background: Copper is one of the heavy metals whose presence in aquatic environment in higher concentration poses a major threat to the environment. This is due to their toxic effects on the plants, animals and human health. Biosorption an innovative biotechnological technique with superior advantages was used for the remediation of $\mathrm{Cu}^{2+}$ from aqueous solution in this study.

Methods: Biosorbent was prepared from raw (RAWB) and oxalic acid modified (OAMB) Saccharum officinarum. They were characterized by scanning electron microscopy (SEM/EDAX), fourier transform infrared (FTIR), and X-ray diffraction (XRD) for surface morphological study. Experimental data obtained from batch equilibrium studies were subjected to two-parameters [Freundlich, Langmuir, Tempkin and Dubinin-Radushkevich (D-R)] and three-parameter [Redlich-Peterson (R-P), Sips, Hill and Toth] isotherm models. Kinetic data were analysed with pseudo first-order, pseudo second-order, Elovich and Avrami kinetic models.

Results: The results of proximate analysis and characterization show that the oxalic acid modification affected the biosorbents content, surface modifications and the functional groups present. The experimental data from the equilibrium studies were best fitted to the isotherms with $R^{2}>0.9$ for the OAMB and RAWB. The adsorption energies (E) from the D-R isotherms were found to be 0.36 and $0.06 \mathrm{~kJ} / \mathrm{mol}$ for OAMB and RAWB respectively, which is indication of physisorption favoured processes. Pseudo second-order model best fitted the data with a coefficient of determination $\left(R^{2}\right)$ of above 0.998 with an average relative and hybrid errors lower than $5 \%$. Intraparticulate diffusion model analysis showed that the adsorption process develops in two stages as rapid and slow phase. Changes in standard free energy $\left(\Delta G^{\circ}\right)$, enthalpy $\left(\Delta H^{\circ}\right)$ and entropy $\left(\Delta S^{\circ}\right)$ for the biosorption processes were estimated using the thermodynamic equilibrium model. The calculated thermodynamics parameters indicated that the process is spontaneous and endothermic in nature.
\end{abstract}

Conclusions: This study revealed the feasibility of $\mathrm{Cu}^{2+}$ removal through biosorption processes using S. officinarum biomass as biosorbent. The improved surface morphology for increase biosorption by oxalic acid modification is also favourable. The biosorption process for the removal of the $\mathrm{Cu}^{2+}$ is $\mathrm{pH}$ dependent as the efficiency increased from 36.4 to $65.3 \%$ for raw biomass while the OAMB has increase efficiency from 57.5 to 88.6 as the pH increases from 2 to 6 .

Keywords: Saccharum officinarum, Oxalic acid, Biosorption, Kinetics, Thermodynamics, Equilibrium

\footnotetext{
*Correspondence: abuaisha2k3@yahoo.com

${ }^{1}$ Chemistry Department, Federal University of Agriculture, Abeokuta,

Nigeria

Full list of author information is available at the end of the article
}

\section{黛 Springer}

(c) 2016 Adeogun et al. This article is distributed under the terms of the Creative Commons Attribution 4.0 International License (http://creativecommons.org/licenses/by/4.0/), which permits unrestricted use, distribution, and reproduction in any medium, provided you give appropriate credit to the original author(s) and the source, provide a link to the Creative Commons license, and indicate if changes were made. 


\section{Background}

Presence of heavy metals in aquatic environment is a major threat to the environment. This is due to their toxic effects on the plants, animals and human health. Discharge of effluents from industrial activities such as electroplating, mining, electrical and electronics, iron and steel production pharmaceuticals, pesticides, organic chemicals, rubber and plastics, etc. are major sources of the heavy metal contamination in the environment, especially copper. Plants in general are very sensitive to copper toxicity, the effect of its presence at a slightly higher than normal level leads to metabolic disturbances and growth inhibition (Fernandes and Henriques 1991; Hajiboland and Hasani 2007). Damage to marine life and vital organs such as gills, liver, kidneys, the nervous system and changing sexual life of fishes a has been attributed to high concentration of copper (Ajmal et al. 1998; Munagapati et al. 2010).

The health implications of acute copper poisoning in humans includes: itching and dermatization and keratinisation of the hands and soles of feet (Huang et al. 2007), severe gastro-intestinal irritation and possible changes in the liver and kidneys when exposed to large doses, their is increasing of the risk of lung cancer among exposed worker due to the inhalation of copper sprays (Ajmal et al. 1998; Aydin et al. 2008). High level of copper compounds in the body may lead to aging, schizophrenia, mental illness, Indian childhood cirrhosis, Wilson's and Alzheimer's diseases (Brewer 2007; Faller 2009; Haureau and Faller 2009). Copper has also been implicated in the damage to lipids and DNA (Brewer 2010). According to the World Health Organisation (WHO) and United State Environmental Protection Agency (USEPA), the maximum permissible limit of copper in drinking water is $1.3 \mathrm{mg} \mathrm{L}^{-1}$ Bajpai and Jain (2010). It is therefore important to reduce the concentration of copper in industrial effluent to acceptable level before discharge into stream or other receiving water bodies.

New technologies for heavy metal removal from wastewater are desirable due to strict environmental regulations. Readily available technologies (such as; ion exchange, chemical precipitation, oxidation reduction, filtration, electrochemical techniques etc.) are most of time ineffective for the removal of heavy metal ions at low concentrations (below $50 \mathrm{mg} / \mathrm{L}$ ). Furthermore, they may be expensive. Toxic sludge may also be generated with another problem of disposal.

Biosorption is an innovative biotechnology for the removal of metal ion from aqueous solution with superior advantages such; high efficiency and selectivity even at low metal ion concentrations, energy-saving, broad operational range of $\mathrm{pH}$ and temperature, easy reclamation of metals and easy recycling of the biosorbent. Many agricultural and biological based materials have been utilized as biosorbent for $\mathrm{Cu}^{2+}$ biosorption (Hansen et al. 2010), these include: Adathoda vasica (Jafar and Shajudha 2012), coconut husk (Oyedeji and Osinfade 2010; Okafor et al. 2012; Putra et al. 2014), Hevea brasiliensis (Kalavathy and Miranda 2010), and palm kernel fibres (Ho and Ofomaja 2006; Ofomaja 2010), sour orange residue (Khormaei et al. 2007) and brown sea weeds (Antunes et al. 2003) to mention but few.

In this study, we used Saccharum officinarum in its raw form and oxalic acid modification state for the preparation of biosorbents for the removal of copper (II) ion from aqueous solution in a batch process. The effect of solution $\mathrm{pH}$, biosorbent dose, initial metal ion concentrations and contact time were investigated. The equilibrium parameters were analyzed with two-parameters [Freundlich, Langmuir, Tempkin and Dubinin-Radushkevich $(\mathrm{D}-\mathrm{R})$ ] and three-parameter [Redlich-Peterson (R-P), Sips, Hill and Toth] isotherm models. Kinetic data were analysed with pseudo first-order, pseudo second-order, Elovich, Avrami and Intraparticulate diffusion kinetic models. Changes in standard free energy $\left(\Delta G^{\circ}\right)$, enthalpy $\left(\Delta \mathrm{H}^{\circ}\right)$ and entropy $\left(\Delta \mathrm{S}^{\circ}\right)$ for the biosorption processes were estimated and reported using the thermodynamic equilibrium model.

\section{Methods}

\section{Preparation of $\mathrm{Cu}^{2+}$ solution}

Aqueous solutions of $\mathrm{Cu}^{2+}$ of different concentration were prepared from copper nitrate $\left[\mathrm{Cu}\left(\mathrm{NO}_{3}\right)_{2}\right]$ obtained from British Drug House, London. This was used as adsorbate and was not purified prior to use. Double distilled-deionised water was employed for the preparation of all the solutions and reagents.

\section{Preparation of biosorbent}

Saccharum officinarum (sugarcane) was obtained from Lafenwa market in Abeokuta, Nigeria. It was washed thoroughly with de-ionized water, its peels were removed and the juice extracted, the resulting shaft was sun dried for 10 days to obtain S. officinarum bagasse. The dried $S$. officinarum bagasse was then pulverized and sieved through a $100 \mu \mathrm{m}$ mesh copper sieve and kept in air tight container. Oxalic acid modification of the S. officinarum was according to the method described by Park et al. (2005) with a little modification. The process is summarized by Scheme 1 below. Briefly $200 \mathrm{ml}$ of $0.1 \mathrm{M}$ solution of oxalic was thoroughly mixed with $5 \mathrm{~g}$ of the bagasse in a $500 \mathrm{ml}$ beaker. The slurry was then kept in vacuum 


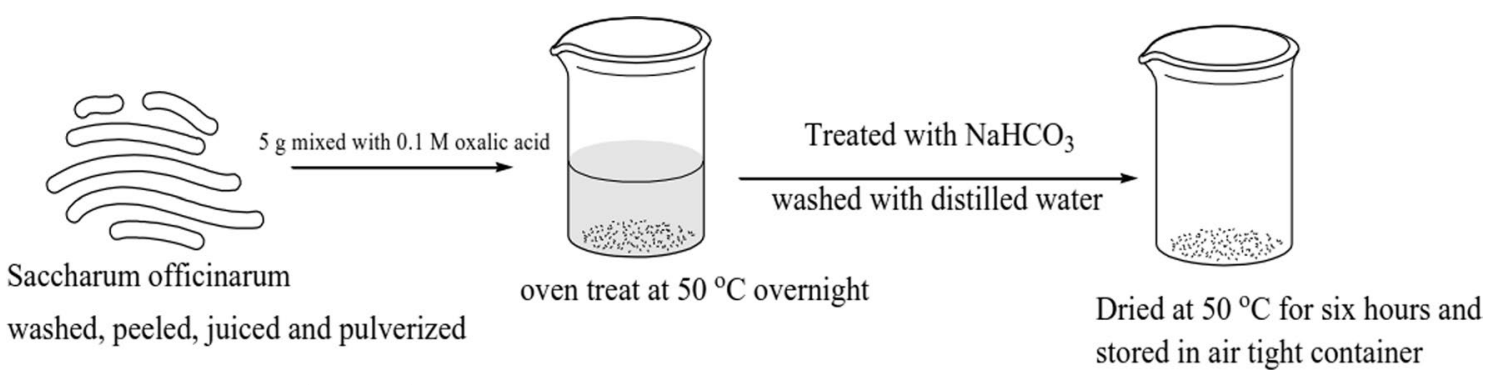

Scheme 1 Preparation and modification of biosorbent

oven at $50{ }^{\circ} \mathrm{C}$ overnight. Sodium bicarbonate was added to remove excess acid then the mixture was washed with distilled water to remove the impurities. The modified biomass were again dried at $50{ }^{\circ} \mathrm{C}$ for $6 \mathrm{~h}$, allowed to cool and then gently stirred with glass rod to return them to powdery form.

\section{Characterization and analytical procedure}

The dried material was characterized by different physico-chemical techniques. Proximate analysis was by ASTM established procedures which covered hemicellulose, cellulose, lignin, moisture, ash and volatile organic matter contents. X-ray diffraction (XRD) data were collected using a PAN Analytical X'Pert PRO X-ray diffractometer with $\mathrm{Cu} \mathrm{K \alpha}$ radiation $(\lambda=1.5418 \AA)$. Fourier transform infrared (FT-IR) spectra were recorded from 400 to $4000 \mathrm{~cm}^{-1}$ in TENSOR 27 spectrometer (Bruker, Germany) using $\mathrm{KBr}$ pellet technique. Surface morphology of the material was analysed using scanning electron microscopy (SEM/EDAX) [VEGA3 TESCAN]. The concentrations of $\mathrm{Cu}^{2+}$ in the solutions before and after adsorption were determined using an atomic absorption spectrophotometer (Buck Scientific model 200 VGP). The samples were filtered prior to analysis in order to minimize interference of the biosorbent with the analysis. Non-linear regression analysis method using a program written on Micro Math Scientist software (Salt Lake City, Utah) was used to obtain the least square fit for all the models.

\section{Batch equilibrium studies}

$100 \mathrm{ml}$ of aqueous solutions of known $\mathrm{Cu}^{2+}$ concentration with a predetermined amount of biosorbent were placed in Erlenmeyer flasks in an orbital shaker. The effects of biosorbent dosage, initial metal concentration, $\mathrm{pH}$ and temperature on the removal of $\mathrm{Cu}^{2+}$ were studied. Sample solutions were withdrawn at intervals to determine the residual copper concentration by using atomic absorption spectrophotometer (Buck Scientific model 200 VGP). The amount of $\mathrm{Cu}^{2+}$ removed at equilibrium, $Q_{\mathrm{e}}\left(\mathrm{mg} \mathrm{g}^{-1}\right)$, was calculated using Eq. 1 below:

$$
Q_{e}=\frac{\left(C_{o}-C_{e}\right) V}{W}
$$

where $C_{o}\left(\mathrm{mg} \mathrm{L}^{-1}\right)$ is the initial concentration and $C_{e}(\mathrm{mg}$ $\mathrm{L}^{-1}$ ) is the concentration of the $\mathrm{Cu}^{2+}$ at equilibrium in the liquid-phase. $V$ is the volume of the solution (L) while $W$ is the mass of the adsorbent.

\section{Effect of biosorbent dosage}

The study of effect of biosorbent dosages on the removal of $\mathrm{Cu}^{2+}$ from aqueous solution was carried-out at different adsorbent doses ranging between 0.1-1.0 g using $100 \mathrm{mg} \mathrm{L}^{-1}$ of the $\mathrm{Cu}^{2+}$ solution. The Erlenmeyer flasks containing the copper solutions of the same initial concentration but different biosorbent mass were placed on orbital shaker at $200 \mathrm{rpm}$. After some time the samples were filtered off and the solution was analyzed for the residual $\mathrm{Cu}^{2+}$.

\section{Effects of initial copper concentration and contact time}

The effects of initial $\mathrm{Cu}^{2+}$ concentration and contact time on biosorption process were investigated with $100 \mathrm{ml} \mathrm{Cu}^{2+}$ solution of initial concentrations between 100 and $500 \mathrm{mg} \mathrm{L}^{-1}$ in series of Erlenmeyer flasks with fixed amount of biosorbent $(0.2 \mathrm{~g})$ on orbital shaker at $200 \mathrm{rpm}$. Samples were withdrawn, filtered off and the solution analyzed for the residual $\mathrm{Cu}^{2+}$ from the aqueous at preset time intervals.

\section{Effect of $\mathrm{pH}$ on adsorption process}

To investigate the effect $\mathrm{pH}$ on the biosorption process, series of experiments were carried out on solutions with initial $\mathrm{pH}$ varied between 2 and 8 . The $\mathrm{pH}$ was adjusted with $0.1 \mathrm{M} \mathrm{NaOH}$ or $0.1 \mathrm{M} \mathrm{HCl}$ and measured using $\mathrm{pH}$ meter. The concentration of the solutions, biosorbent dosage and temperature were held constant at $100 \mathrm{mg}$ $\mathrm{L}^{-1}, 0.2 \mathrm{~g}$ and $30^{\circ} \mathrm{C}$ respectively. 


\section{Adsorption isotherms}

The equilibrium data from this study were described with the eight adsorption isotherm models (i.e. four each of two-parameter and three-parameter isotherm models). The two-parameter models used are Langmuir (1918), Freudlinch (1906), Temkin, (1940) Dubinin and Radushkevich (1947) while Redlich and Peterson, (1959), Sip (1948), Hill (1949) and Tóth (1995) are the three-parameter isotherm models.

\section{Biosorption kinetics studies}

The procedures for the kinetics studies were basically identical to those of equilibrium tests. The aqueous samples were taken at preset time intervals, and the concentrations of the $\mathrm{Cu}^{2+}$ were similarly determined. The amount of metal ion removed at time $t, Q_{t}\left(\mathrm{mg} \mathrm{g}^{-1}\right)$, was calculated using Eq. 2:

$$
Q_{t}=\frac{\left(C_{o}-C_{t}\right) V}{W}
$$

where $C_{o}\left(\mathrm{mg} \mathrm{L}^{-1}\right)$ is the initial concentration and $C_{t}(\mathrm{mg}$ $\left.\mathrm{L}^{-1}\right)$ is the concentration of $\mathrm{Cu}^{2+}$ at time $t$ in the liquidphase. $V$ is the volume of the solution (L), and $W$ is the mass of the biosorbent.

In order to investigate the mechanisms of the adsorption process, pseudo-first order (Ho and McKay 1999), pseudo-second-order (Ho and McKay 1998), Avrami (1940) and Elovich (Zeldowitsch 1934) models respectively were applied to describe the kinetics of biosorption of $\mathrm{Cu}^{2+}$ during the process. Due to the fact that the diffusion mechanism cannot be obtained from the kinetics model, the intraparticlate diffusion model (Lin et al. 2011) was also tested. A model is adjudged best-fit and selected based on statistical parameters.

\section{Statistical test for the kinetics data}

The acceptability and hence the best fit of the kinetic data were based on the square of the correlation coefficients $R^{2}$ and the percentage error function which measures the differences (\% SSE) in the amount of the metal ion adsorbed at equilibrium predicted by the models, $\left(Q_{\text {cal }}\right)$ and the actual, (i.e. $Q_{\text {exp }}$ ) measured experimentally. The validity of each model was determined by the average relative error (SSE \%) and Hybrid error analysis given by:

$\% S S E=\frac{100}{N} \sqrt{\left(\left(Q_{(\exp )}-Q_{(\text {cal })}\right) / Q_{\exp }\right)^{2}}$.

$\% H Y B R I D=\frac{100}{N-P} \sqrt{\left(\left(Q_{(\exp )}-Q_{(\text {cal })}\right) / Q_{\text {exp }}\right)^{2}}$.

$N$ is the number of data points $P$ is the numbers of the parameters in the kinetic equation. The higher is the value of $R^{2}$ and the lower the value of error, the best fitted the data.

\section{Thermodynamics of the biosorption process}

The thermodynamics parameters i.e. $\Delta G \circ, \Delta H \circ$ and $\Delta S \circ$ were estimated using the following relation:

$$
\begin{aligned}
& \Delta G^{0}=-R T \ln K_{d} \\
& \ln K_{d}=\frac{\Delta S^{0}}{R}-\frac{\Delta H^{0}}{R T}
\end{aligned}
$$

The equilibrium constant, $K_{d}$, is obtained from the value of $Q_{e} / C_{e}$ at different temperature equilibrium study. Van't Hoff plot of $\ln K_{d}$ against the reciprocal of temperature $(1 / \mathrm{T})$, should give a straight line with intercept as $\frac{\Delta S^{0}}{R}$ and slope as $\frac{\Delta H^{0}}{R}$.

\section{Result and discussion}

\section{Batch equilibrium studies}

\section{Characterization of the biosorbent}

The proximate analysis of $S$. officinarum is presented in Table 1 . The volatile matter and ash contents in were 14.89 and $7.6 \%$, respectively. The moisture content was $8.21 \%$. Cellulose, hemicellulose and lignin constitute $23.3,28.2$ and $17.8 \%$ respectively.

SEM micrographs of the modified and raw biosorbents are shown in Fig. 1a, b, it is clearly shown from the figures that effect of modification is the enhanced contour on the surface. The powder layer exhibited a porous microstructure with micropores which were relatively well separated and homogeneously distributed over the surface. The EDX analysis of the two samples further confirmed the effect of modifications as the exposed carbon atom increases from 54.84 to 56.18 upon oxalic acid modification.

The XRD patterns for the modified (a) and raw (b) biosorbent are shown in Fig. 2. For the oxalic acid modified (OAMB) biomass four peaks were noted to appear at $2 \theta=5.3,15.8,22.4$ and 35.3. Similar peaks appeared in the XRD pattern of the raw sample (Fig. $2 b$ ) however, the

Table 1 The proximate analysis of S. officinarum

\begin{tabular}{lc}
\hline Component & $\begin{array}{l}\text { Amount of the } \\
\text { component (\%) }\end{array}$ \\
\hline Hemicellulose & 23.30 \\
Cellulose & 28.20 \\
Lignin & 17.80 \\
Moisture & 8.21 \\
Ash & 7.60 \\
Volatile matter & 14.89 \\
\hline
\end{tabular}



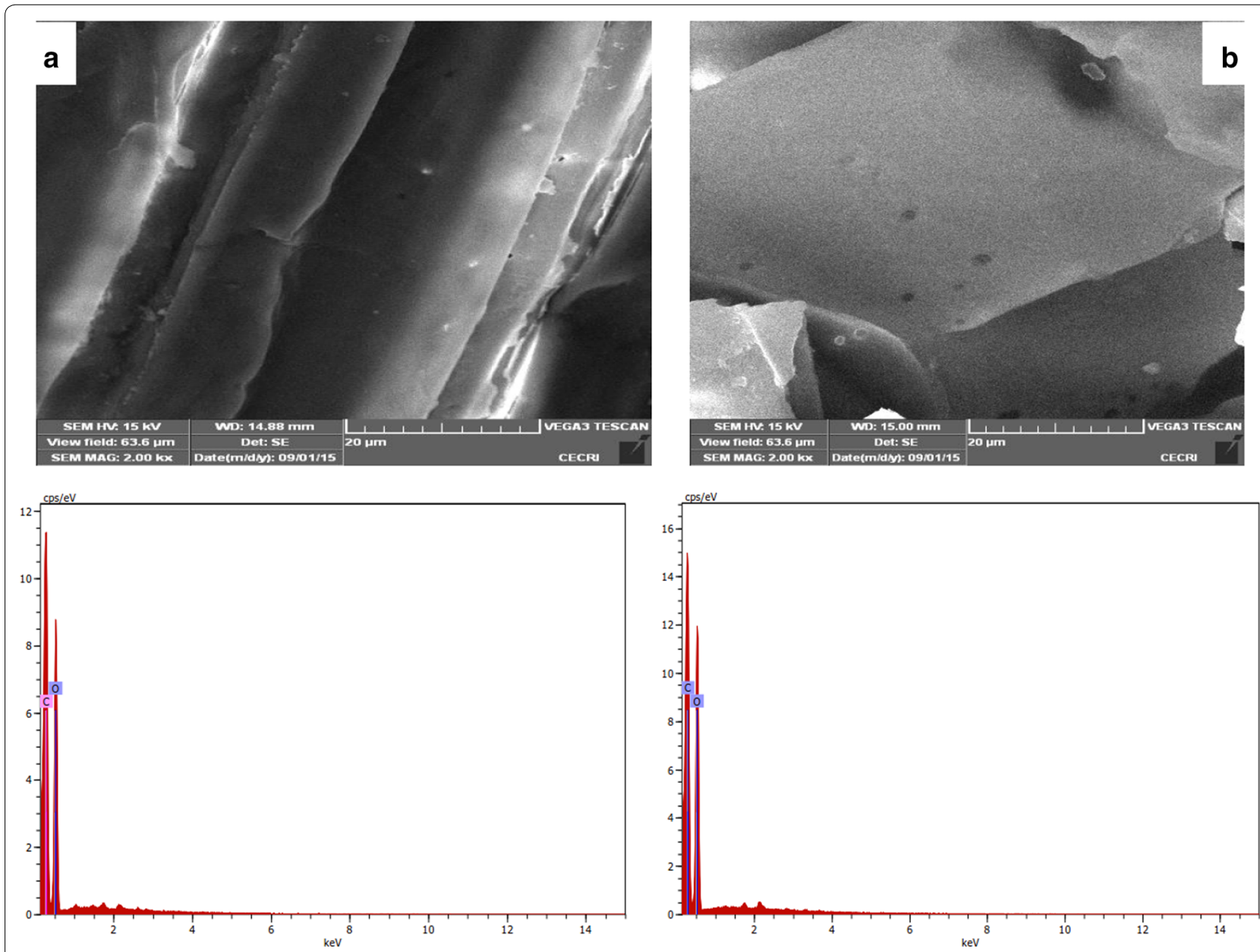

Fig. 1 SEM and EDAX Analysis of (a) Oxalic acid modified and (b) Raw biosorbent

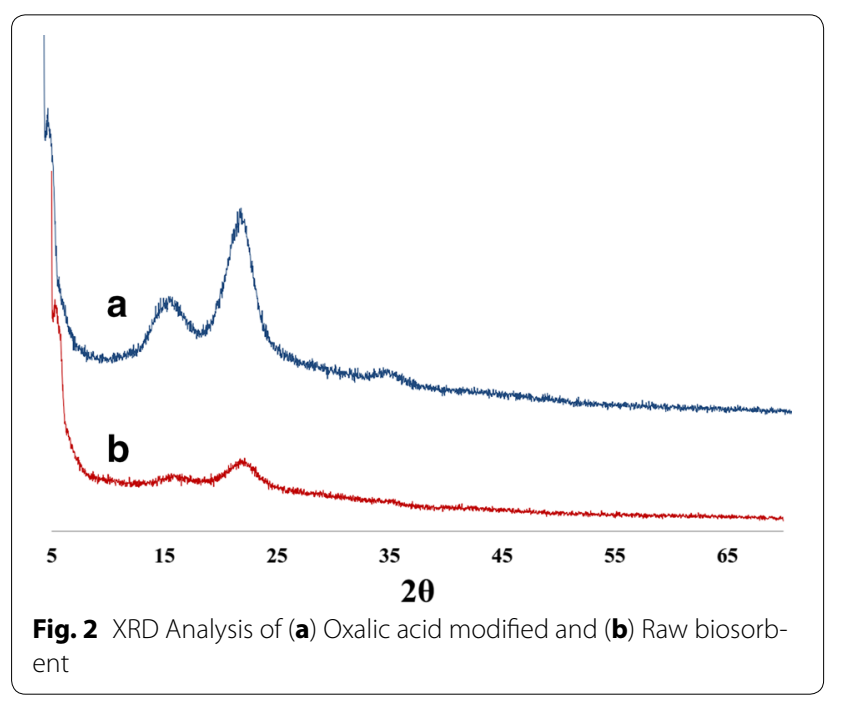

intensity is so low compared with the modified biomass. The modification may therefore be concluded to have improved the crystallinity of the biomass.

Biosorption of metal ion from aqueous solution depends on the functional groups present on the biosorbent, their quantity and affinity for the metal ion. The presence of functional groups on the surface of biosorbents was confirmed before and after biosorption using FTIR analysis as shown in Figs. 3 and 4 for the modified and the raw biomass. FTIR spectra of the raw biomass (Fig. 4b) showed the broad band centered between 3398.37 and $3024.20 \mathrm{~cm}^{-1}$ is attributed to the stretching of hydroxyl groups. The absorption at $2902 \mathrm{~cm}^{-1}$ arises from $\mathrm{C}-\mathrm{H}$ stretching. The small absorbances at 1637, 1600, 1512, 1425, 1371 and $1325 \mathrm{~cm}^{-1}$ correspond to the aromatic skeletal 


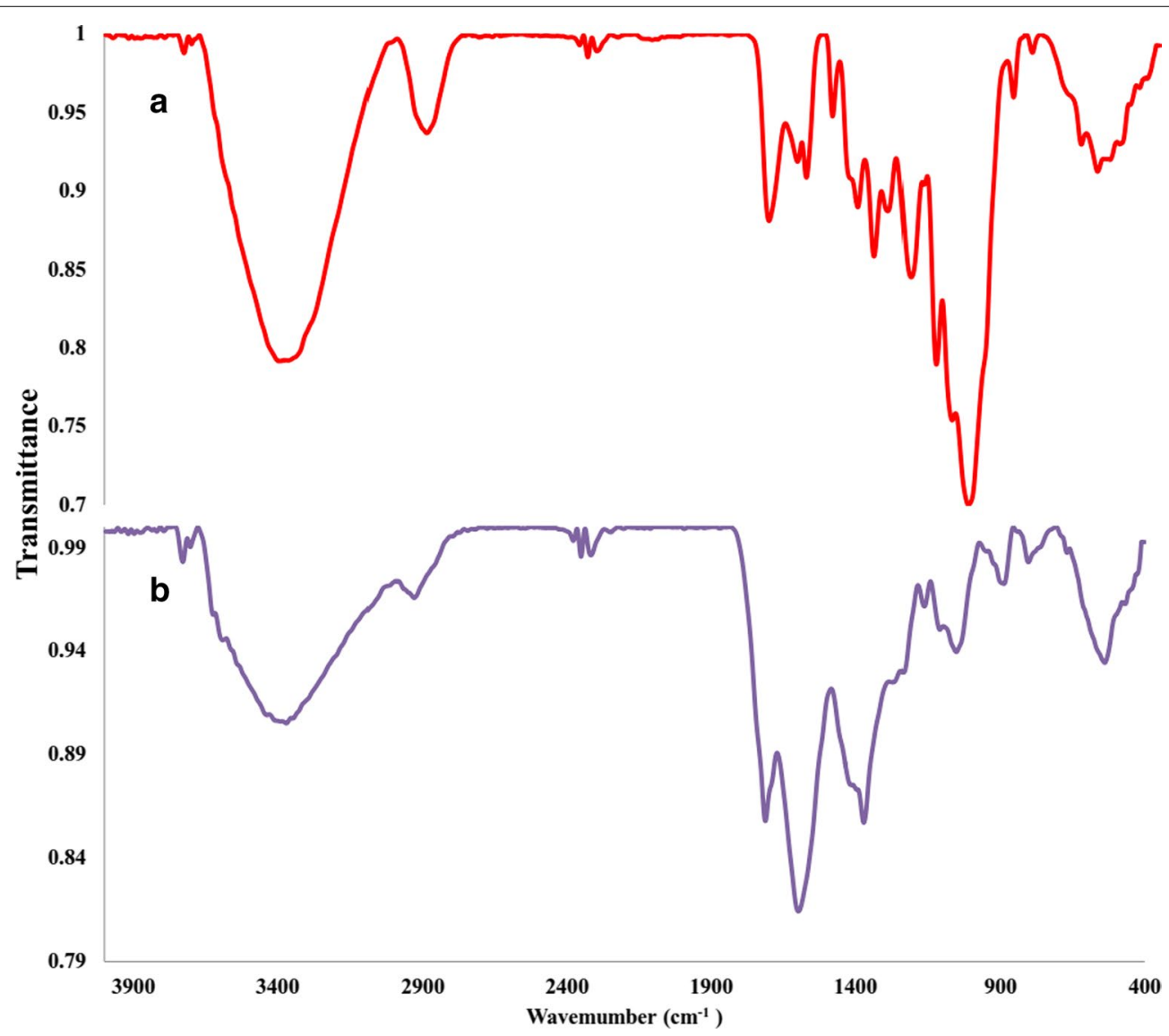

Fig. 3 FTIR spectrum of Oxalic acid modified biosorbent (a) before and (b) after biosorption

vibrations, ring breathing with $\mathrm{C}-\mathrm{O}$ stretching in lignins (Sun et al. 2003). The bands at 1371 and $1247 \mathrm{~cm}^{-1}$ are attributed to absorption by $\mathrm{C}-\mathrm{H}$ and $\mathrm{C}-\mathrm{O}$ stretching in acetyl group in hemicelluloses, respectively. The strong band at $1056 \mathrm{~cm}^{-1}$ is assigned to $\mathrm{C}-\mathrm{O}$ stretching in cellulose, hemicelluloses, and lignin or $\mathrm{C}-\mathrm{O}-\mathrm{C}$ stretching in cellulose and hemicelluloses. The small sharp band at $899 \mathrm{~cm}^{-1}$ originated from the L-glucosidic linkages between the sugar units in hemicelluloses and cellulose. A small band observed at $1732 \mathrm{~cm}^{-1}$ is due to the absorption of carbonyl stretching of ester and carboxyl groups in hemicelluloses. When compared with the spectrum of OAMB biomass (Fig. 3a) additional absorption peaks were noted which confirmed the modification. Upon loaded with copper (Figs. 3b and 4b), the FTIR spectrum of both the raw and modified biomass show reduced peak and lower intensity, which is also a confirmation of interactions of the functional groups with $\mathrm{Cu}^{2+}$. Table 2 summarizes the effects of modification and interactions of the $\mathrm{Cu}^{2+}$ with the raw and modified biomas.

\section{Effect of biosorbent doasge}

Figure 5 shows the plot of biosorbent dosage against the percentage $\mathrm{Cu}^{2+}$ removal process. As shown in the figure, as the quantity of the biosorbent increased from 0.1 to $0.2 \mathrm{~g}$ the $\% \mathrm{Cu}^{2+}$ ion removed increases from 64 to $79 \%$ for RAWB while the increase is from 80 to $97 \%$ for OAMB. Upon increasing the biosorbent dosage, an increase in the percentage removal was noted which climaxed at biosorbent dosage of $0.2 \mathrm{~g}$. Increased $\mathrm{Cu}^{2+}$ removal with increasing biosorbent dosage is attributed to the increase of total adsorbent surface area and adsorption sites, while the subsequent reduction in the percentage removal at biosorbent dosage above $0.2 \mathrm{~g}$ may be attributed to to the particle interactions, such as aggregation, resulting from high adsorbent concentrations which lead to a reduction of the active surface area of the biosorbent (Kakavandi et al. 2015).

\section{Effect of $\mathrm{pH}$ on biosorption process}

Changes in the solution $\mathrm{pH}$ has significant effects on the surface functional groups of the biosorbent as well as the 


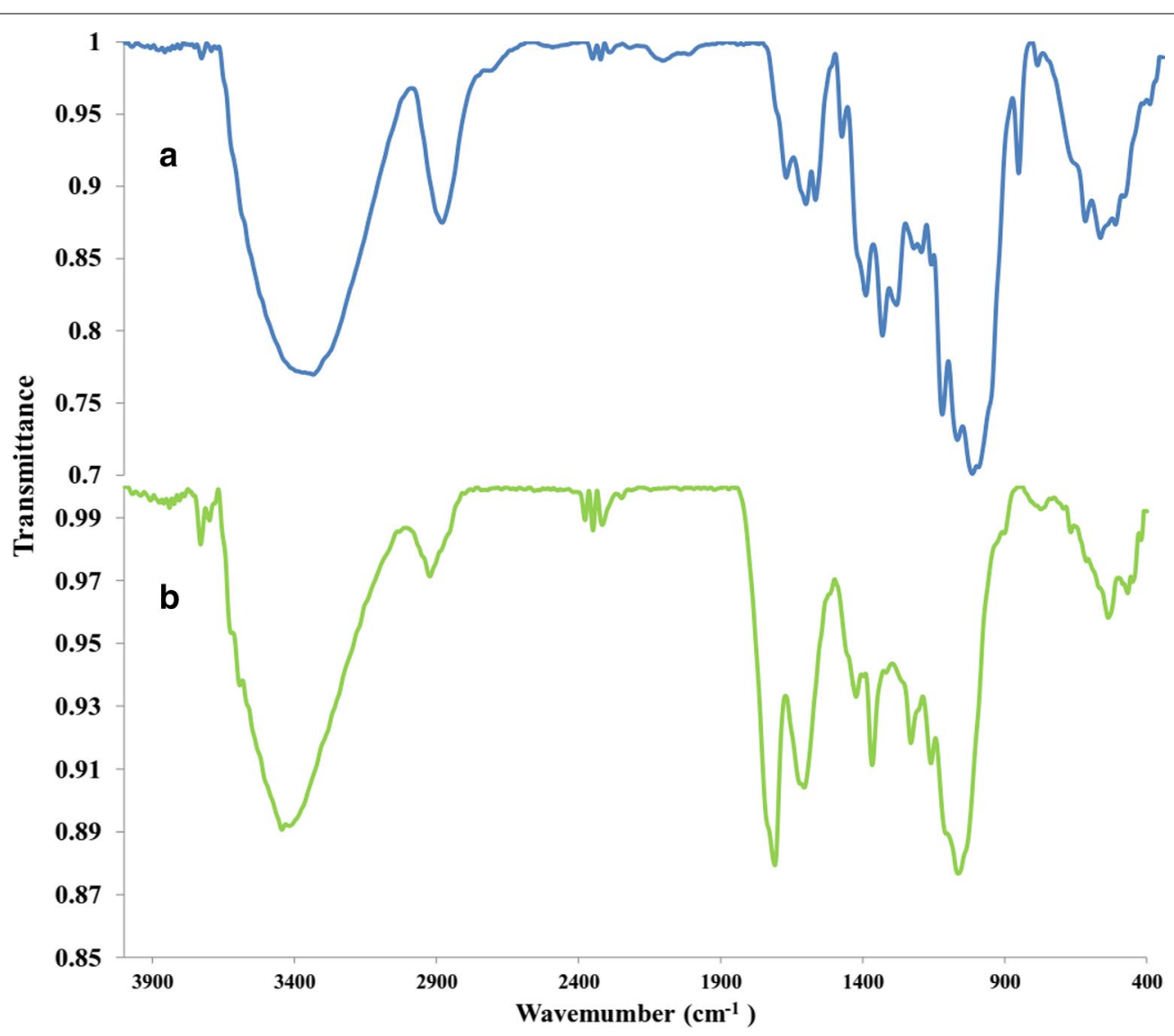

Fig. 4 FTIR spectrum of raw biosorbent (a) before and (b) after biosorption

Table 2 FTIR analysis of the raw and modified biomas before and after biosorption

\begin{tabular}{|c|c|c|c|c|}
\hline Functional group & RAWB & OAMB & Cu-RAWB & Cu-OAMB \\
\hline Hydroxyl group & $3398-3024$ & 3699-3003 & $3676-2993$ & $3673-3040$ \\
\hline -CH-stretching & 2903 & 2899 & 2928 & 2932 \\
\hline Carbonyl stress & 1732 & 1705 & 1713 & 1711 \\
\hline Aromatic skeletal vibrations $\mathrm{C}-\mathrm{O}$ stretching in Lignin & 1637 & 1637 & 1599 & 1605 \\
\hline Aromatic skeletal vibrations $\mathrm{C}-\mathrm{O}$ stretching in Lignin & 1601 & 1603 & & \\
\hline Aromatic skeletal vibrations $\mathrm{C}-\mathrm{O}$ stretching in Lignin & 1512 & 1510 & & \\
\hline Aromatic skeletal vibrations $\mathrm{C}-\mathrm{O}$ stretching in Lignin & 1425 & 1423 & & 1423 \\
\hline$-\mathrm{CH}$-streching & 1371 & 1367 & 1373 & 1367 \\
\hline Ring breathings & 1325 & 1319 & & \\
\hline Ring breathings & 1248 & 1267 & & 1231 \\
\hline Ester group & & 1198 & & \\
\hline Ester group & 1163 & 1161 & 1163 & 1165 \\
\hline Ester group & & 1105 & & \\
\hline CH-streching Hemicellulose & & 1051 & 1053 & 1061 \\
\hline L-Glucosidic linkages & & 897 & 891 & \\
\hline
\end{tabular}

$\mathrm{Cu}^{2+}$ species present in the solution, hence $\mathrm{pH}$ is one of the most influencing parameters in the biorption process. The results of the effect of $\mathrm{pH}$ in variations on the percentage of $\mathrm{Cu}^{2+}$ biosorbed by OAMB and RAWB are shown in Fig. 6. As can be seen, the adsorption capacity increases by increasing the $\mathrm{pH}$ of the solution from 2 to 


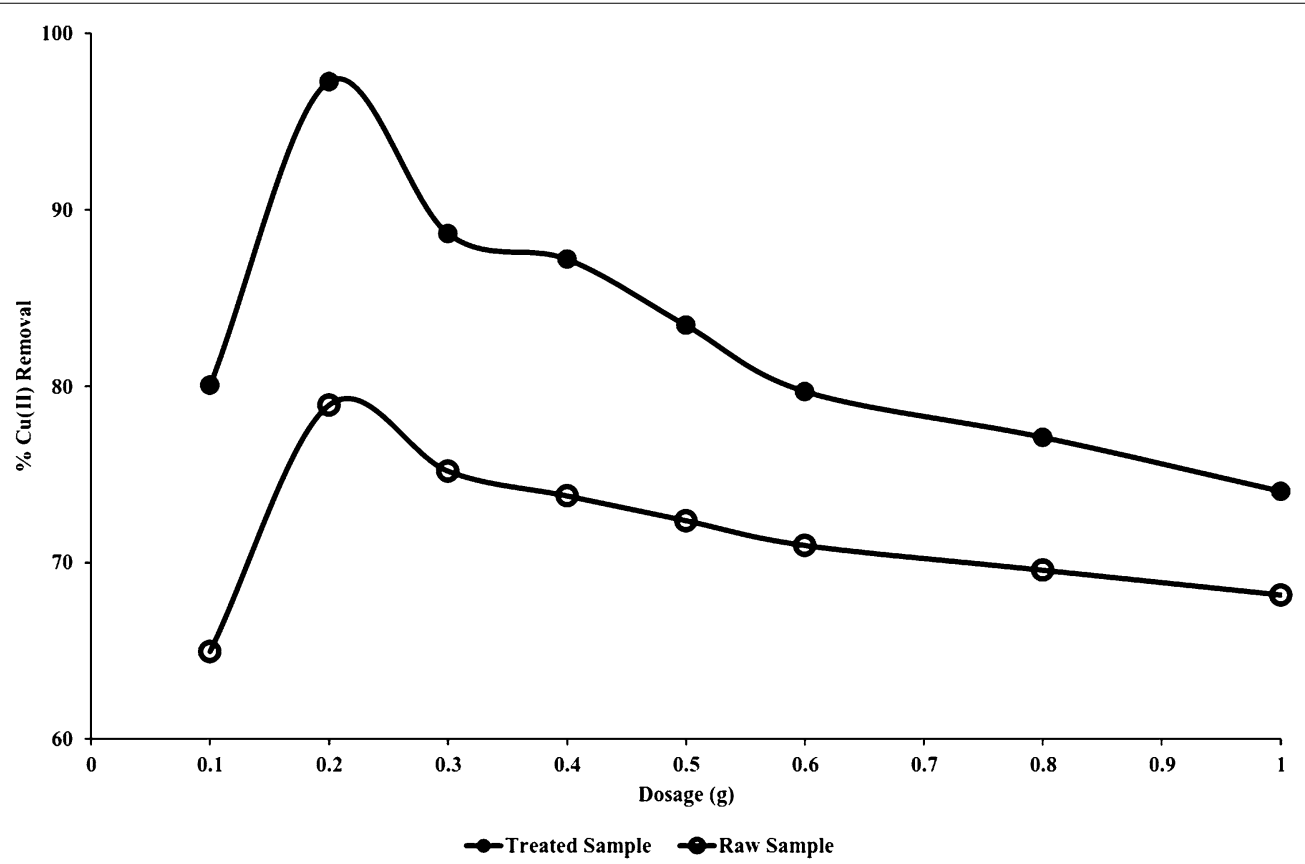

Fig. 5 Effect of biosorbent dosage on removal of $\mathrm{Cu}^{2+}$ from aqeous solution. Condition: $\mathrm{pH} 6,\left[\mathrm{Cu}^{2+}\right]=100 \mathrm{mg} / \mathrm{L} \mathrm{Temperature}=30^{\circ} \mathrm{C}$

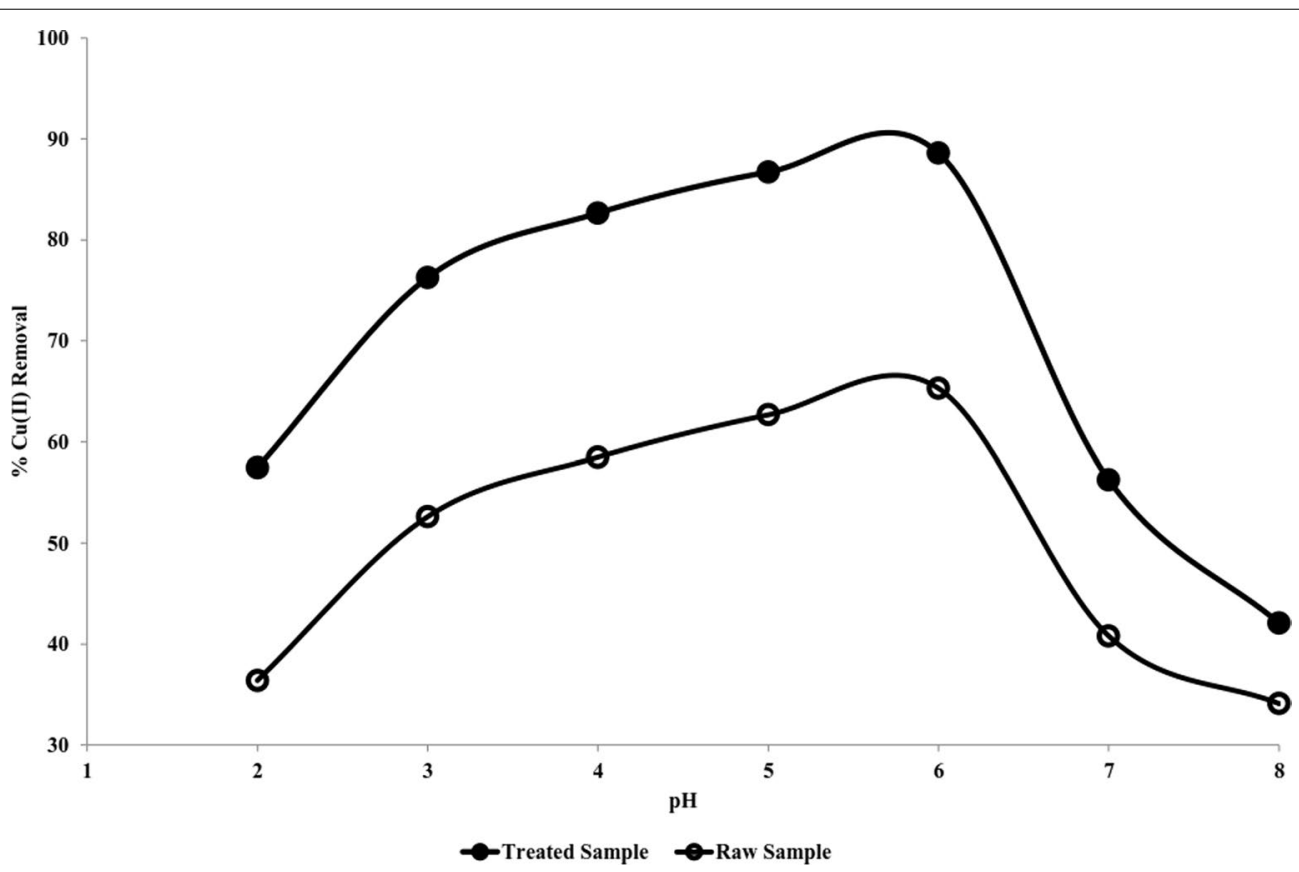

Fig. 6 Effect of $\mathrm{pH}$ dosage on removal of $\mathrm{Cu}^{2+}$ from aqeous solution. Condition: Biosorbent dosage $=0.2 \mathrm{~g},\left[\mathrm{Cu}^{2+}\right]=100 \mathrm{mg} / \mathrm{L} \mathrm{Tempera-}$ ture $=30^{\circ} \mathrm{C}$ 
6. The positive charge that predominate the biosorbent surface due to protonation leading to repulsion of $\mathrm{Cu}^{2+}$ may be responsible for the lower removal efficiency at low $\mathrm{pH}$, however as the $\mathrm{pH}$ increases from 2 to 6 completion for the biosorption sites reduces and more $\mathrm{Cu}^{2+}$ are removed from the solution. As the solution approaches basic $\mathrm{pH}$, precipitation of the metal ion may be responsible for the decrease in the percentage metal ion removed (Vukovic et al. 2011).

\section{Effect of initial $\mathrm{Cu}^{2+}$ concentrations}

The effect of initial metal ion concentration on the biosorption process is shown in Fig. 7a, b. The process showed a rapid removal in the first $20 \mathrm{~min}$ for all the concentrations studied. The efficiency of the process increases from 48.4 to $220.75 \mathrm{mg} \mathrm{g}^{-1}$ for OAMB and 39.8 to 181.4 for RAWB as the initial concentration of $\mathrm{Cu}^{2+}$ increase from 100 to $500 \mathrm{mg} \mathrm{L}^{-1}$. The observed increased in the biosorption capacity as the concentration increases may be due to the increased driving force of the concentration gradient. As there is no significant difference in the quantity of the $\mathrm{Cu}^{2+}$ after $60 \mathrm{~min}$ of the process, a steady-state approximation was assumed and a quasiequilibrium situation was reached.

\section{Adsorption study \\ Adsorption isotherms}

The bisorption equilibrium data obtained at different initial $\mathrm{Cu}^{2+}$ concentrations were fitted into eight different isotherm models. The equation representing these models and the parameters are summarized in Table 3 the detail of which have been explained elsewhere (Foo and Hameed 2010; Adeogun and Balakrishnan 2015a, b). The acceptability and suitability of the isotherm equation to
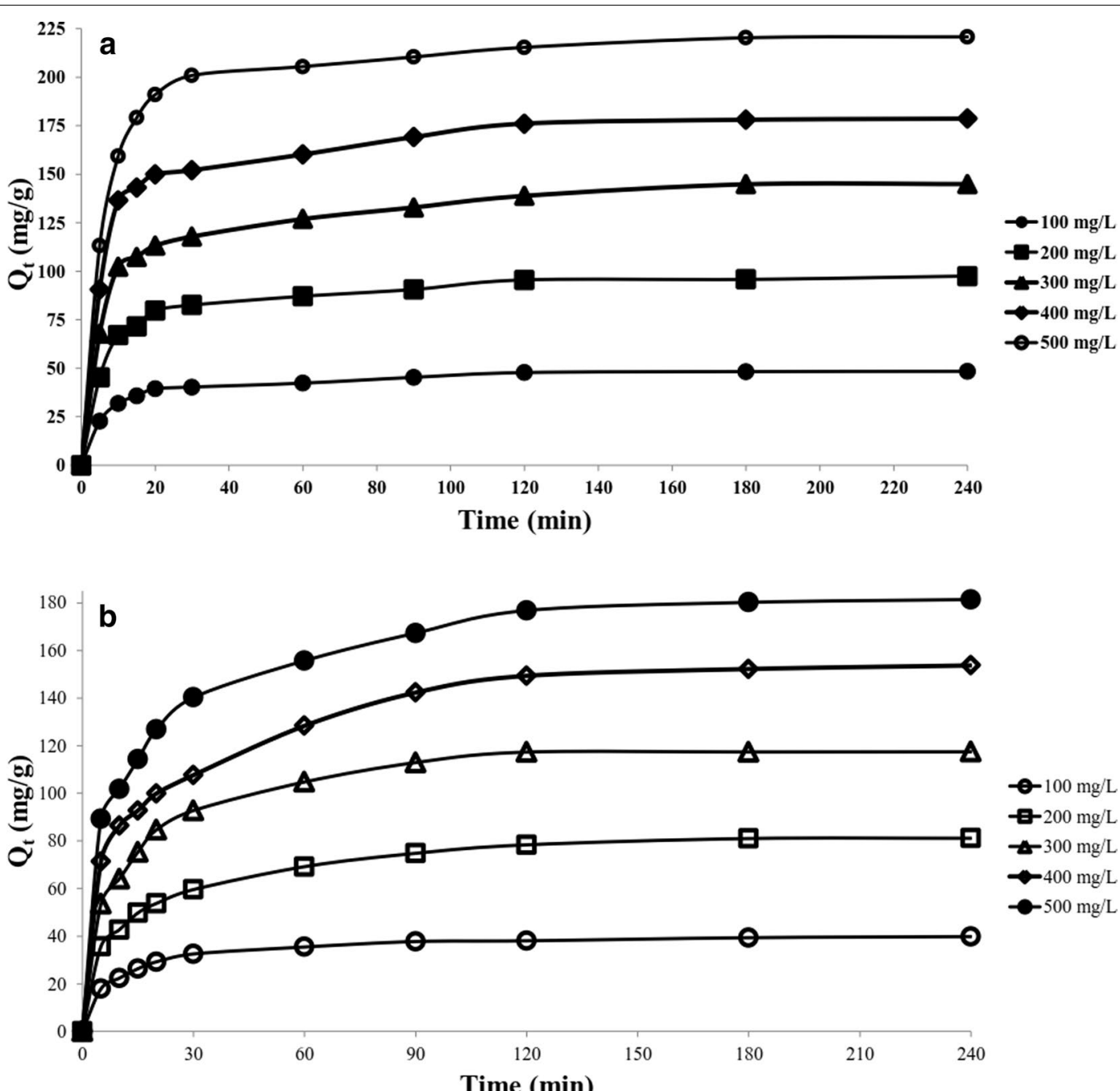

Fig. 7 Effect of initial concentration on removal of $\mathrm{Cu}^{2+}$ from aqeous solution (a) Oxalic acid modified and (b) Raw biosorbent. Condition: Biosorbent dosage $=0.2 \mathrm{~g}$, $\mathrm{pH}=6$ Temperature $=30^{\circ} \mathrm{C}$ 

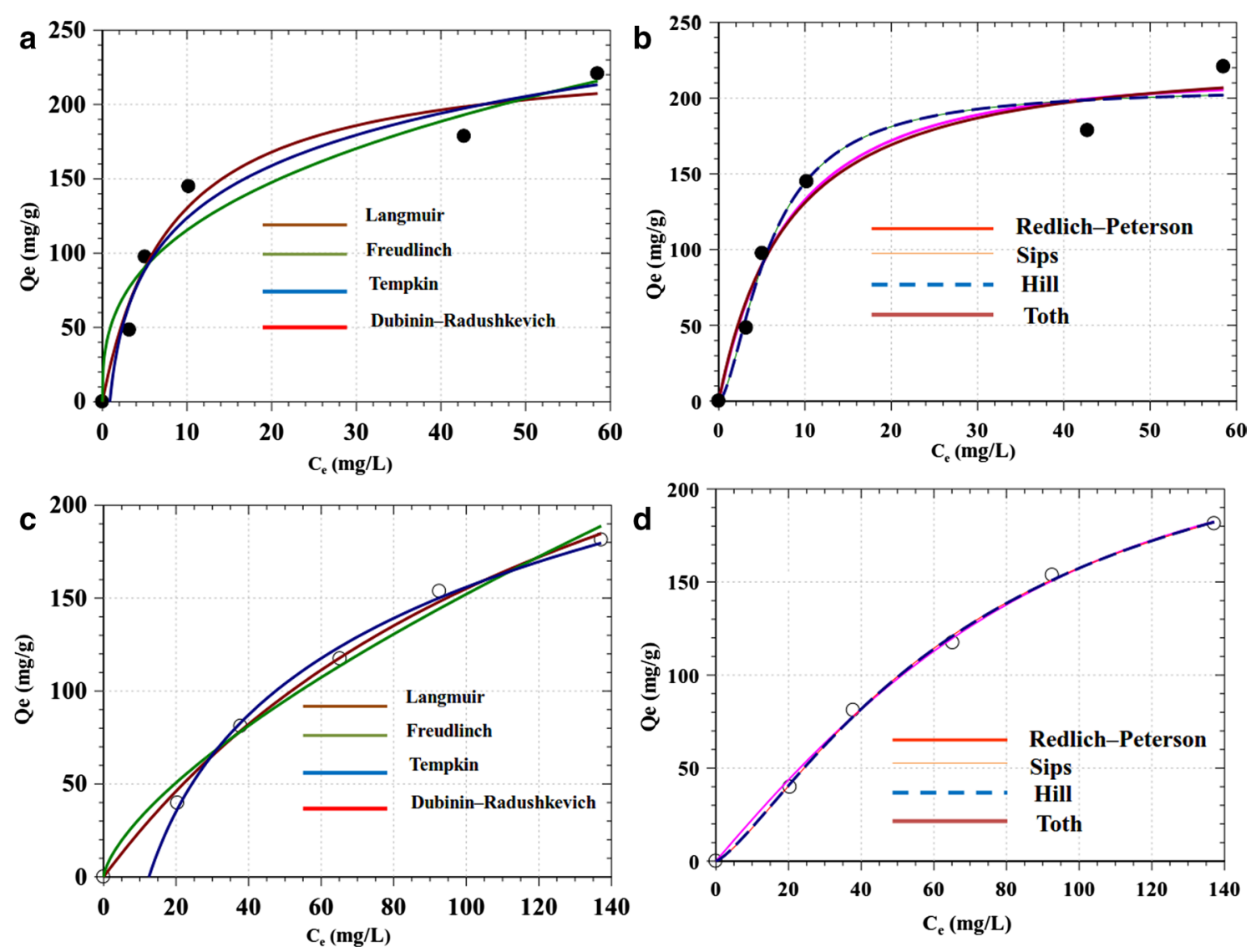

Fig. 8 Isothemal fits for the biosorption process, (a) and (c) are two-parameter fit while $(\mathbf{b})$ and (d) are three-parameter fit Oxalic acid modified and Raw biosorbent

the equilibrium data were based on the values of the correlation coefficients, $R^{2}$ estimated from linear regression of the least square fit statistic on Micro Math Scientist software. Figure 8 represents the biosorption isotherm for OAMB ( $a$ and $b$ ) and RAWB (c and d), the parameters for these isotherm fit are presented in Table 4. The adsorption data fitted well with Dubinin-Radushkevich and Sip's isotherms with the highest $\mathrm{R}^{2}$ (Table 4). The data fitted well with all the Isotherms for the RAWB and OAMB with $R^{2}>0.98$. The $n$ value of $>1$ and the $R L$ of $<1$ obtained for Freudlinch and Langmuir isotherms are indication that the adsorption is favorable on the investigated biosorbents. The maximum adorption isotherm of The mean biosorption energy $\mathrm{E}$ obtained from DubininRadushkevich was 0.06 and $0.39 \mathrm{~kJ} \mathrm{~mol}^{-1}$ for OAMB and RAWB which is an indication of physiorption (Table 4) dominated processes, similar observation had been reported in the literature (Veli and Alyüz 2007).
Table 3 Isotherm models used for the study of the biosorption of $\mathrm{Cu}^{2+}$ on Oxalic acid modified and raw Saccharum officinarum biomas

\begin{tabular}{lll}
\hline Isotherm name & Isotherm model & Parameters \\
\hline Langmuir & $Q_{e}=\frac{Q_{\max } b C_{e}}{1+b C_{e}}$ & $Q_{\max }$ and $\mathrm{b}$ \\
Freudlinch & $\mathrm{Q}_{e}=K_{\mathrm{F}} C^{1 / n}$ and $\mathrm{n}$ \\
Temkin & $Q_{e}=\frac{R T}{B_{T}} \ln \left(A_{T} C_{e}\right)$ & \\
Dubinin-Radushkevich & $Q_{e}=Q_{s} E x p\left(-\frac{\left(R T \ln \left(1+\frac{1}{C_{e}}\right)\right)^{2}}{2 E^{2}}\right)$ & $Q_{s}$ and $\mathrm{E}$ \\
Redlich-Peterson & $Q_{e}=\frac{Q_{e} C_{e}}{\left(1+K_{R} C_{e}^{g}\right)}$ & $Q_{O^{\prime}} K_{R}$ and $g$ \\
Sip & $Q_{e}=\frac{Q_{s}\left(K_{s} C_{e}\right)_{S}}{\left(1+\left(K_{S} C_{e}\right)^{\beta_{S}}\right)}$ & $Q_{s^{\prime}} K_{s}$ and $\beta_{s}$ \\
Hill & $Q_{H^{\prime}} K_{H}$ and $n_{H}$ \\
Toth & $Q_{e}=\frac{Q_{H} C_{e}^{n_{H}}}{\left(K_{H}+C_{e}^{n+H}\right)}$ & $Q_{T}, K_{T}$ and $t$ \\
\hline
\end{tabular}


Table 4 Isotherm parameters for the biosorption of $\mathrm{Cu}^{2+}$ on Oxalic acid modified and raw Saccharum officinarum biomas

\begin{tabular}{|c|c|c|c|}
\hline & & Oxalic acid modified biomas & Raw raw biomas \\
\hline \multirow[t]{4}{*}{ Langmuir } & $Q_{\max }\left(m g g^{-1}\right)$ & 379.15 & 236.16 \\
\hline & $\mathrm{b}\left(\mathrm{L} \mathrm{mg}^{-1}\right)$ & 0.0069 & 0.12 \\
\hline & $R_{L}$ & 0.36 & 0.04 \\
\hline & $R^{2}$ & 0.999 & 0.990 \\
\hline \multirow[t]{3}{*}{ Freudlinch } & $\mathrm{K}_{\mathrm{F}}\left(\mathrm{mg} \mathrm{g}^{-1}\left(\mathrm{mg} \mathrm{L}^{-1}\right)^{-1 / n}\right)$ & 6.55 & 51.13 \\
\hline & $\mathrm{n}$ & 1.46 & 2.83 \\
\hline & $R^{2}$ & 0.996 & 0.983 \\
\hline \multirow[t]{3}{*}{ Tempkin } & $A_{T}\left(L^{-1}\right)$ & 0.08 & 1.14 \\
\hline & $\mathrm{B}_{\mathrm{T}}\left(\mathrm{J} \mathrm{mol}^{-1} \mathrm{~g} \mathrm{mg}^{-1}\right)$ & 33.06 & 49.62 \\
\hline & $R^{2}$ & 0.999 & 0.989 \\
\hline \multirow[t]{3}{*}{ Dubinin-Radushkevich } & $Q_{s}\left(\mathrm{mg} \mathrm{g}^{-1}\right)$ & 172.08 & 195.14 \\
\hline & $\mathrm{E}\left(\mathrm{kJ} \mathrm{mol}^{-1}\right)$ & 0.06 & 0.39 \\
\hline & $R^{2}$ & 0.984 & 0.989 \\
\hline \multirow[t]{4}{*}{ Redlich-Peterson } & $Q_{0}\left(\mathrm{mg} \mathrm{g}^{-1}\right)$ & 2.28 & 26.39 \\
\hline & $K_{R}\left(\mathrm{mg}^{-1} \mathrm{~g}\right)^{1 / g}$ & 0.000513 & 0.0845 \\
\hline & g & 1.47 & 1.07 \\
\hline & $R^{2}$ & 0.999 & 0.990 \\
\hline \multirow[t]{4}{*}{ Sips } & $Q_{s}\left(m g g^{-1}\right)$ & 258.63 & 207.09 \\
\hline & $K_{S}\left(m g^{-1} L\right)_{S}^{1 / \beta}$ & 0.014 & 0.17 \\
\hline & $\beta_{s}$ & 1.32 & 1.61 \\
\hline & $R^{2}$ & 0.999 & 0.992 \\
\hline \multirow[t]{4}{*}{ Hill } & $Q_{H}\left(\mathrm{mg} \mathrm{g}^{-1}\right)$ & 262.65 & 207.09 \\
\hline & $K_{H}\left(m g^{-1} L\right)_{H}^{1 / n}$ & 269.23 & 17.58 \\
\hline & $\mathrm{n}_{\mathrm{H}}$ & 1.30 & 1.61 \\
\hline & $R^{2}$ & 0.999 & 0.992 \\
\hline \multirow[t]{4}{*}{ Toth } & $Q_{T}\left(m g g^{-1}\right)$ & 142.99 & 270.12 \\
\hline & $K_{T}\left(\mathrm{mg} \mathrm{L}^{-1}\right)$ & 108.91 & 8.88 \\
\hline & t & 1.18 & 0.97 \\
\hline & $R^{2}$ & 0.999 & 0.990 \\
\hline
\end{tabular}

\section{Kinetics of biosorption}

The plots of four different kinetic models used to explain the adsorption data are shown in Fig. 9a, b. The equations for these models are shown in Table 5, details of which have been explained elsewhere (Adeogun et al. 2012; Lin et al. 2011; Ahmad et al. 2014; Adeogun and Balakrishnan 2015a, b). From the kinetic parameters for the biosorption as shown in Table 6, pseudo-second-order kinetic models best fitted the kinetic data for both OAMB and RAWB. The rate constant decreases with increase initial $\mathrm{Cu}^{2+}$ concentration, showing that at higher initial concentration the electrostatic interaction decreases at the site, thereby lowering the biosorption rate. The values of $Q_{e}$ obtained from the second order model compared favourably well with the experimental values with the estimated errors less than $5 \%$. The behaviour of Elovich constant shows that the process of biosorption is more than one mechanism.

\section{Adsorption mechanism}

The mechanism of biosorption was investigated by subjecting the data to intraparticulate diffusion model. The plots are shown in Fig. 10. The linearity of the plot is not over the whole time range rather they exhibit multi-linearity revealing the existence of two successive adsorption steps. The first stage is faster than the second, and it is attributed to the external surface adsorption referred to as the boundary layer diffusion. Thereafter, the second linear part is attributed to the intraparticle diffusion stage; this stage is the rate controlling step. Table 7 shows the intraparticle model constants for the biosorption of $\mathrm{Cu}^{2+}$ on OAMB and RAWB. The $K_{d i}$ values were found to increase from first stage of adsorption toward the second stage. The increase in $\mathrm{Cu}^{2+}$ concentration results in an increase in the driving force thereby increasing the diffusion rate. 

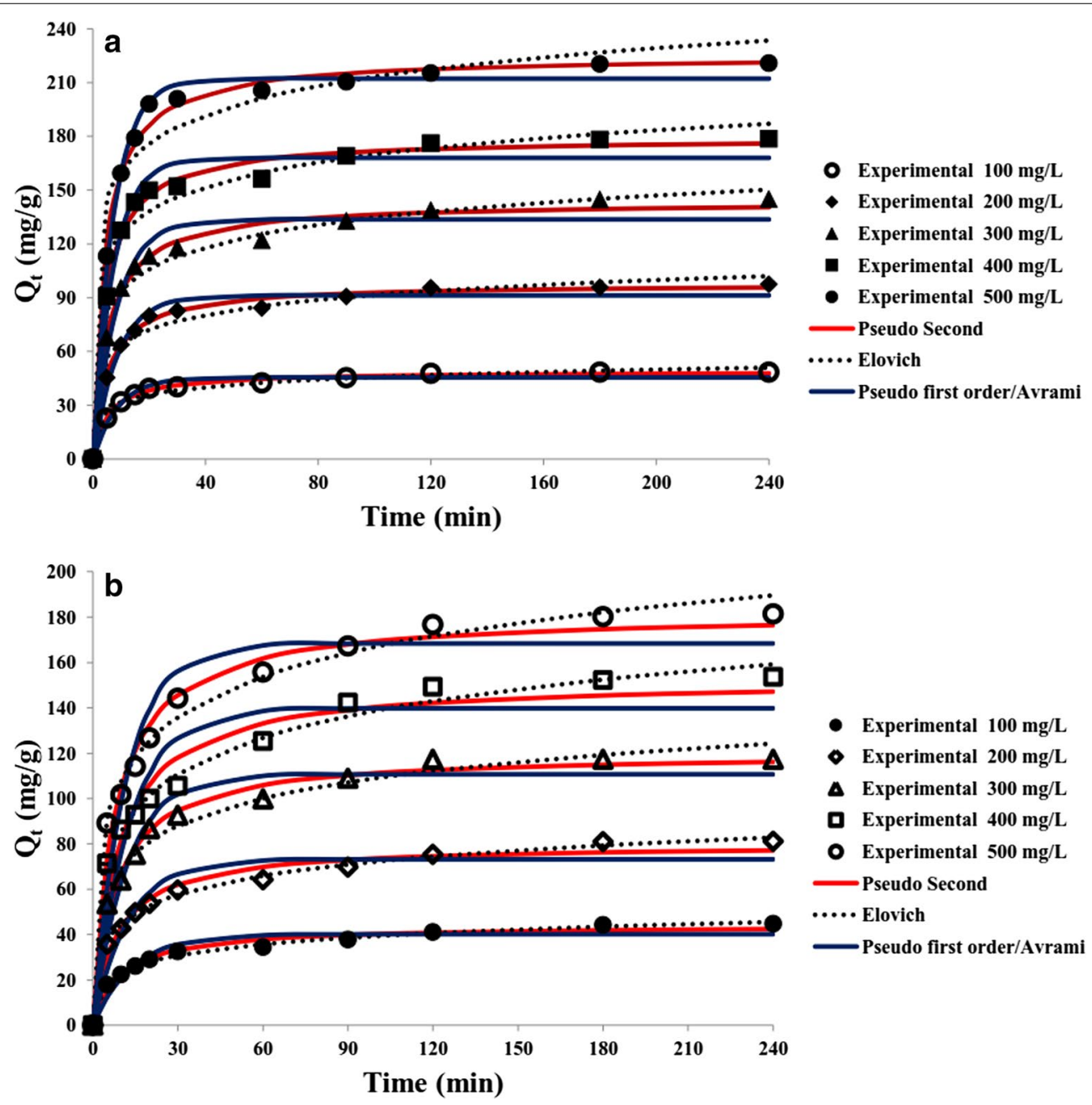

Fig. 9 Kinetic fits for the biosorption process, Oxalic acid modified (a) and Raw biosorbent (b)

Table 5 Kinetic models for the biosorption of $\mathrm{Cu}^{2+}$ on Oxalic acid modified and raw Saccharum officinarum biomas

\begin{tabular}{lll}
\hline Isotherm name & Isotherm model & Parameters \\
\hline Pseudo first order & $Q_{t}=Q_{e}\left(1-e^{\left(-k_{1} t\right)}\right)$ & $Q_{e}$ and $k_{1}$ \\
Pseudo second order & $Q_{t}=\frac{Q_{e}^{2} k_{2} t}{\left(1+Q_{e} k_{2} t\right)}$ & $Q_{e}$ and $k_{2}$ \\
Elovich & $Q_{t}=\frac{1}{\beta} \ln (\alpha \beta t)$ & $a$ and $\beta$ \\
Avramin & $Q_{t}=Q_{e}\left(1-e^{\left(-k_{a v} t\right)^{n a v}}\right)$ & $K_{a v}$ and $n_{a v}$ \\
Intraparticulate model & $Q_{t}=K_{i d} t^{0.5}+C_{i}$ & $K_{i d}$ and $C_{i}$ \\
\hline
\end{tabular}

\section{Thermodynamic parameters}

The free energy change, $\Delta \mathrm{G}$ is obtained from Eqs. (5 and 6) according to the van't Hoff linear plots of ln $K_{d}$ versus $1 / \mathrm{T}$ plot in Fig. 11. The thermodynamic parameters are presented in Table 8 . Increasing negative $\Delta G$ values with increasing temperature is an indication that the biosorption processes is spontaneous and feasible. Positive value of enthalpy change $(\Delta \mathrm{H})$ indicates that the adsorption process is endothermic in nature. Positive value of entropy change shows the increased randomness of the solid-liquid interface during the biosorption processes. 
Table 6 Kinetic parameters for the biosorption of $\mathrm{Cu}^{2+}$ on Oxalic acid modified and raw Saccharum officinarum biomas

\begin{tabular}{|c|c|c|c|c|c|c|c|c|c|c|c|}
\hline & \multirow[b]{2}{*}{$C_{o}\left(\mathrm{mg} \mathrm{L}^{-1}\right)$} & \multicolumn{5}{|c|}{ Oxalic acid modified biomas } & \multicolumn{5}{|c|}{ Raw raw biomas } \\
\hline & & 100 & 200 & 300 & 400 & 500 & 100 & 200 & 300 & 400 & 500 \\
\hline & $C_{e}\left(\mathrm{mg} \mathrm{L}^{-1}\right)$ & 3.20 & 5.04 & 10.20 & 42.74 & 58.50 & 20.40 & 37.80 & 65.20 & 92.60 & 137.20 \\
\hline & $Q_{\exp }\left(m g g^{-1}\right)$ & 48.4 & 97.48 & 144.9 & 178.63 & 220.75 & 39.8 & 81.1 & 117.4 & 153.7 & 181.4 \\
\hline \multirow[t]{5}{*}{ Pseudo first-order } & Qe $\left(\mathrm{mg} \mathrm{g}^{-1}\right)$ & 45.54 & 91.62 & 134.13 & 168.29 & 211.69 & 37.58 & 75.88 & 112.47 & 142.34 & 169.06 \\
\hline & $k_{1} \times 10^{-2}\left(\min ^{-1}\right)$ & 11.4 & 11.8 & 12.3 & 14.6 & 13.7 & 8.73 & 7.37 & 8.00 & 7.62 & 8.57 \\
\hline & $R_{2}$ & 0.997 & 0.997 & 0.995 & 0.997 & 0.999 & 0.996 & 0.992 & 0.994 & 0.988 & 0.991 \\
\hline & $\triangle \mathrm{Qe}_{\text {SSE }}$ & 0.59 & 0.60 & 0.74 & 0.58 & 0.41 & 0.56 & 0.64 & 0.42 & 0.74 & 0.68 \\
\hline & $\triangle \mathrm{Qe} \mathrm{HYBRID}_{\mathrm{H}}$ & 0.66 & 0.67 & 0.83 & 0.64 & 0.46 & 0.62 & 0.72 & 0.47 & 0.82 & 0.76 \\
\hline \multirow[t]{5}{*}{ Pseudo second-order } & Qe $\left(\mathrm{mg} \mathrm{g}^{-1}\right)$ & 48.88 & 98.11 & 144.00 & 179.37 & 224.75 & 40.59 & 82.71 & 121.82 & 154.73 & 182.67 \\
\hline & $k_{2} \times 10^{-3}\left(\mathrm{~g} \mathrm{mg}^{-1} \mathrm{~min}^{-1}\right)$ & 3.65 & 1.92 & 1.33 & 1.34 & 1.04 & 3.26 & 1.30 & 0.98 & 0.73 & 0.72 \\
\hline & $R^{2}$ & 0.999 & 0.999 & 0.999 & 0.999 & 0.999 & 0.999 & 0.998 & 0.999 & 0.996 & 0.998 \\
\hline & $\Delta \mathrm{Qe}_{\mathrm{SSE}}$ & 0.10 & 0.07 & 0.06 & 0.04 & 0.18 & 0.20 & 0.20 & 0.38 & 0.07 & 0.07 \\
\hline & $\triangle Q e_{H Y B R I D}$ & 0.11 & 0.07 & 0.07 & 0.05 & 0.20 & 0.22 & 0.22 & 0.42 & 0.07 & 0.08 \\
\hline \multirow[t]{6}{*}{ Elovich } & $a\left(\operatorname{mg}(g \min )^{-1}\right)$ & 109.76 & 275.87 & 408.82 & 1522.13 & 1946.75 & 35.10 & 40.75 & 81.44 & 87.92 & 154.74 \\
\hline & $\beta\left(\mathrm{g} \mathrm{mg}^{-1}\right)$ & 0.16 & 0.08 & 0.06 & 0.05 & 0.04 & 0.17 & 0.08 & 0.06 & 0.04 & 0.04 \\
\hline & $Q_{e t=0}\left(\mathrm{mg} \mathrm{g}^{-1}\right)$ & 6.09 & 11.85 & 17.44 & 18.96 & 23.59 & 5.77 & 12.83 & 17.98 & 23.49 & 26.09 \\
\hline & $R^{2}$ & 0.997 & 0.996 & 0.995 & 0.992 & 0.993 & 0.998 & 0.999 & 0.999 & 0.999 & 0.999 \\
\hline & $\Delta \mathrm{Qe}_{\text {SSE }}$ & 3.58 & 8.53 & 13.29 & 16.80 & 21.01 & 2.53 & 6.53 & 10.21 & 13.84 & 16.70 \\
\hline & $\triangle \mathrm{Qe} \mathrm{HYBRID}_{\mathrm{H}}$ & 3.98 & 9.48 & 14.76 & 18.67 & 23.34 & 2.81 & 7.25 & 11.34 & 15.38 & 18.56 \\
\hline \multirow[t]{6}{*}{ Avramin } & Qe $\left(\mathrm{mg} \mathrm{g}^{-1}\right)$ & 45.54 & 91.62 & 134.13 & 168.29 & 211.69 & 37.58 & 75.88 & 112.47 & 142.34 & 169.06 \\
\hline & $k_{1}\left(\min ^{-1}\right)_{a v}^{n}$ & 0.28 & 0.48 & 0.27 & 0.36 & 0.42 & 0.24 & 0.38 & 0.21 & 0.24 & 0.35 \\
\hline & $n_{a v}$ & 0.41 & 0.24 & 0.46 & 0.40 & 0.33 & 0.36 & 0.19 & 0.38 & 0.31 & 0.24 \\
\hline & $R^{2}$ & 0.997 & 0.997 & 0.995 & 0.997 & 0.999 & 0.996 & 0.992 & 0.994 & 0.988 & 0.991 \\
\hline & $\Delta \mathrm{Qe}_{\text {SSE }}$ & 0.59 & 0.60 & 0.74 & 0.58 & 0.41 & 0.56 & 0.64 & 0.42 & 0.74 & 0.68 \\
\hline & $\triangle Q e_{\text {HYBRID }}$ & 0.66 & 0.67 & 0.83 & 0.64 & 0.46 & 0.62 & 0.72 & 0.47 & 0.82 & 0.76 \\
\hline
\end{tabular}

\section{Conclusion}

This study revealed the feasibility $\mathrm{Cu}^{2+}$ through biosorption processes using S. officinarum biomass as biosorbent. The improved surface morphology for increase biosorption by oxalic acid modification is also favourable. The biosorption process for the removal of the $\mathrm{Cu}^{2+}$ is $\mathrm{pH}$ dependent as the efficiency increased from 36.4 to $65.3 \%$ for raw biomass while the OAMB has increase efficiency from 57.5 to 88.6 as the $\mathrm{pH}$ increases from 2 to 6 . Equilibrium data fitted very well in the Langmuir isotherm equation, confirming the monolayer adsorption capacity of 379.15 for OAMB and $236.16 \mathrm{mg} \mathrm{g}^{-1}$ for RAWB. The 

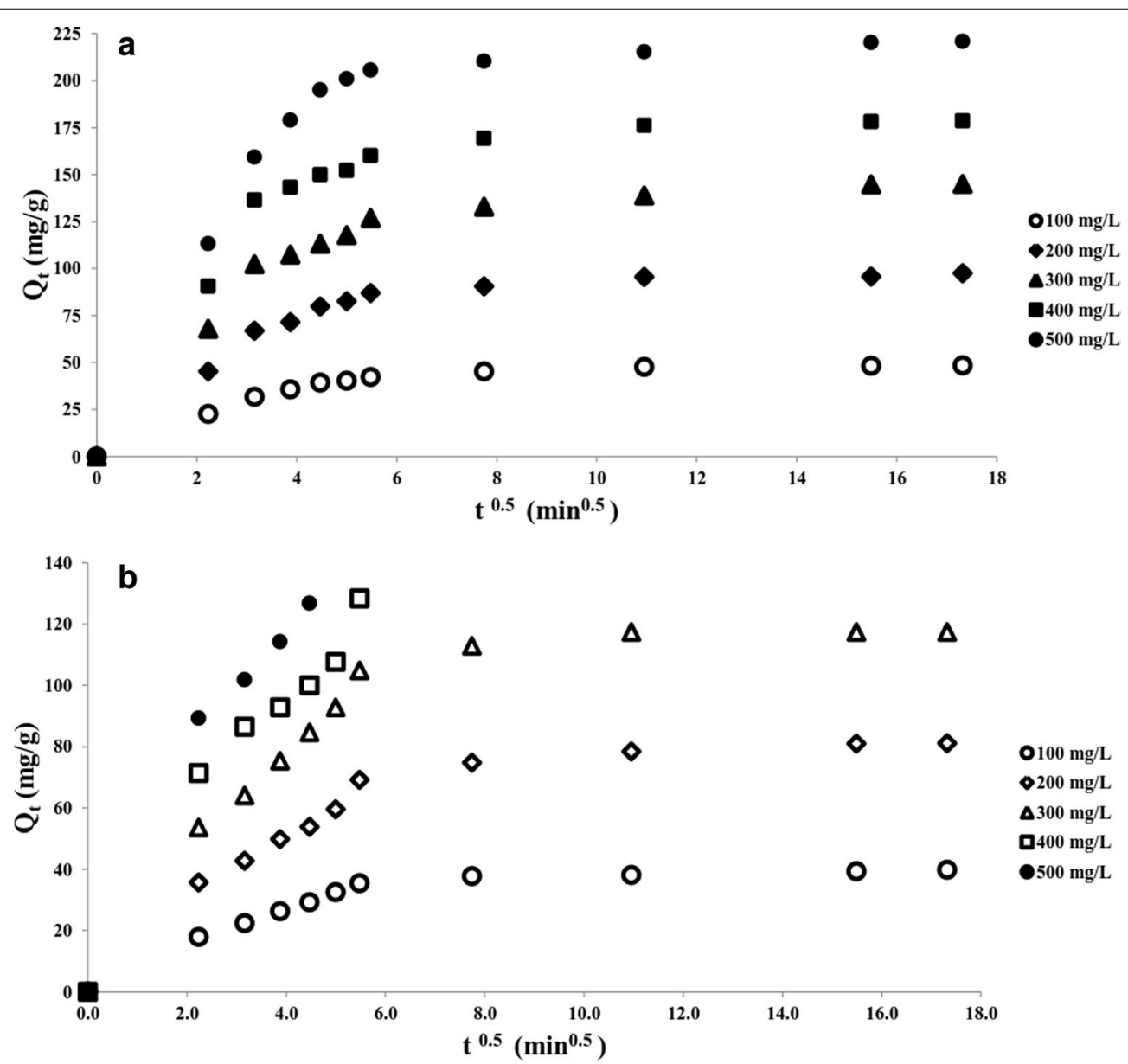

Fig. 10 Intraparticulate diffusion fit for the biosorption process, Oxalic acid modified (a) and Raw biosorbent (b)

Table 7 Intraparticulate diffusion parameters for the biosorption of $\mathrm{Cu}^{2+}$ on Oxalic acid modified and raw Saccharum officinarum biomas

\begin{tabular}{|c|c|c|c|c|c|c|c|c|c|c|}
\hline \multirow[b]{2}{*}{$C_{0}\left(m g ~ L^{-1}\right)$} & \multicolumn{5}{|c|}{ Oxalic acid modified biomas } & \multicolumn{5}{|c|}{ Raw raw biomas } \\
\hline & 100 & 200 & 300 & 400 & 500 & 100 & 200 & 300 & 400 & 500 \\
\hline$K_{1 d}\left(\mathrm{mg} \mathrm{g}^{-1} \mathrm{~min}^{-0.5}\right)$ & 8.31 & 16.92 & 24.12 & 31.58 & 41.31 & 6.29 & 11.79 & 18.23 & 21.28 & 26.71 \\
\hline$C_{1}\left(\mathrm{mg} \mathrm{g}^{-1}\right)$ & 2.38 & 4.82 & 9.24 & 13.37 & 12.17 & 1.59 & 3.59 & 4.80 & 10.15 & 11.58 \\
\hline$R^{2}$ & 0.971 & 0.968 & 0.944 & 0.931 & 0.97 & 0.989 & 0.978 & 0.986 & 0.952 & 0.966 \\
\hline$K_{2 d}\left(\mathrm{mg} \mathrm{g}^{-1} \mathrm{~min}^{-0.5}\right)$ & 0.47 & 0.80 & 1.52 & 1.42 & 1.28 & 0.32 & 0.94 & 0.91 & 1.87 & 2.00 \\
\hline$C_{2}\left(\mathrm{mg} \mathrm{g}^{-1}\right)$ & 41.03 & 84.12 & 120.27 & 156.20 & 199.82 & 34.38 & 66.15 & 103.59 & 123.90 & 149.49 \\
\hline$R^{2}$ & 0.811 & 0.869 & 0.955 & 0.83 & 0.962 & 0.891 & 0.883 & 0.687 & 0.813 & 0.861 \\
\hline
\end{tabular}

kinetics of the process is best explained using a pseudo second-order kinetics model, with higher $\mathrm{R}^{2}>0.99$. Intraparticle diffusion was not the sole rate controlling factor.
The thermodynamics parameters obtained indicates that the process is spontaneous endothermic nature of the process. Therefore, the present findings suggested 


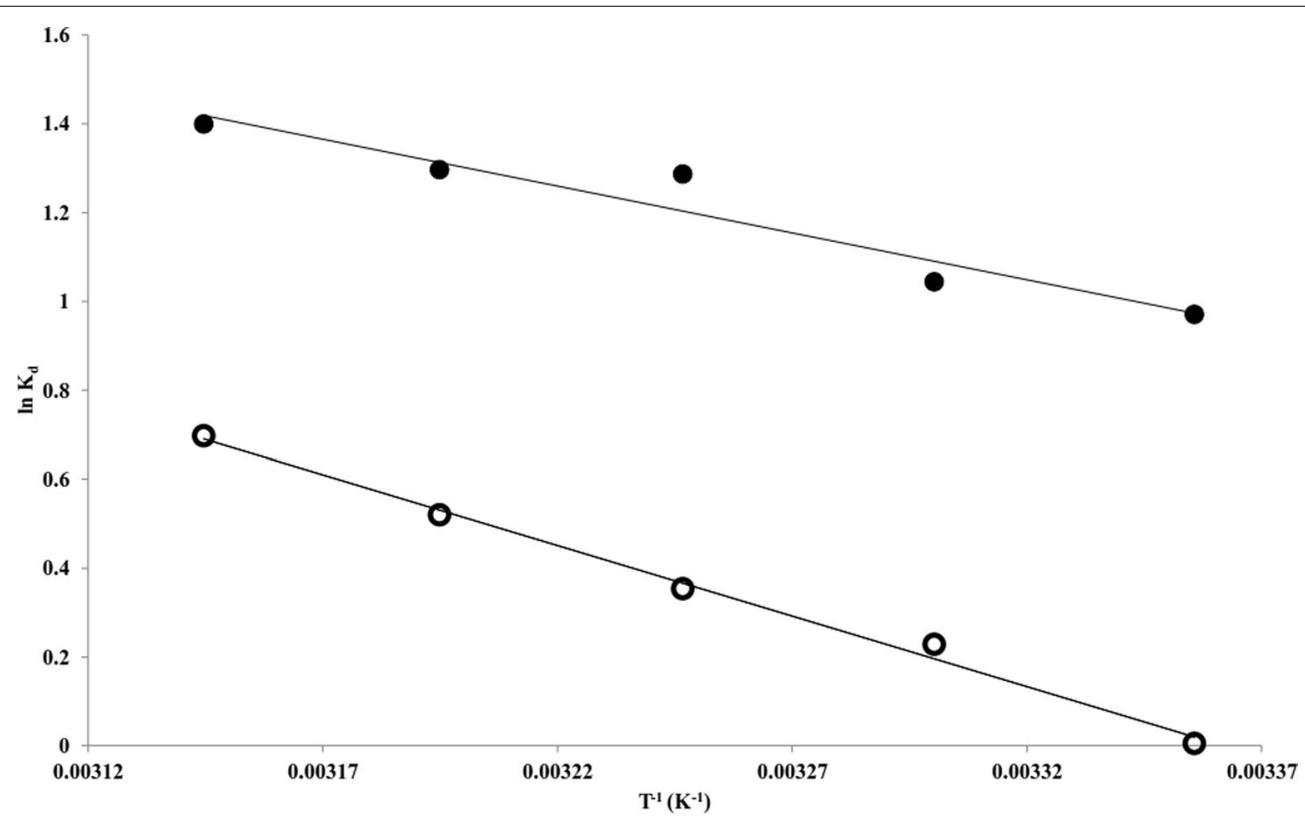

- Treated Sample ORaw Sample

Fig. 11 Thermodynamic fit for the biosorption process, Oxalic acid modified (closed circle) and Raw biosorbent (open circle)

Table 8 Thermodynamic parameters for the biosorption of $\mathrm{Cu}^{2+}$ on Oxalic acid modified and raw Saccharum officinarum biomas

\begin{tabular}{|c|c|c|c|c|c|c|c|c|c|c|}
\hline \multirow[b]{2}{*}{ Temp } & \multicolumn{5}{|c|}{ Oxalic acid modified biomas } & \multicolumn{5}{|c|}{ Raw raw biomas } \\
\hline & $K_{d}$ & $\Delta \mathrm{G}\left(\mathrm{kJ} \mathrm{mol}{ }^{-1}\right)$ & $\Delta \mathrm{H}\left(\mathrm{kJ} \mathrm{mol}{ }^{-1}\right)$ & $\Delta \mathrm{S}\left(\mathrm{J} \mathrm{mol}^{-1}\right)$ & $R^{2}$ & $K_{d}$ & $\Delta \mathrm{G}\left(\mathrm{kJ} \mathrm{mol}{ }^{-1}\right)$ & $\Delta \mathrm{H}\left(\mathrm{kJ} \mathrm{mol}{ }^{-1}\right)$ & $\Delta \mathrm{S}\left(\mathrm{J} \mathrm{mol}^{-1}\right)$ & $\Delta \mathrm{G}\left(\mathrm{kJ} \mathrm{mol}{ }^{-1}\right)$ \\
\hline 298 & 2.639 & -2.40 & 17.55 & 66.99 & 0.927 & 1.005 & -0.01 & 26.43 & 88.86 & 0.994 \\
\hline 303 & 2.840 & -2.63 & & & & 1.257 & -0.58 & & & \\
\hline 308 & 3.622 & -3.30 & & & & 1.424 & -0.91 & & & \\
\hline 313 & 3.656 & -3.37 & & & & 1.682 & -1.35 & & & \\
\hline 318 & 4.054 & -3.70 & & & & 2.009 & -1.84 & & & \\
\hline
\end{tabular}

a better performance of removal of $\mathrm{Cu}^{2+}$ by biosorption process and that modification of S. officinarum with oxalic acid enhanced its performance.

\section{Authors' contributions}

AlA designed the experiment, characterized the biosorbent and prepared the manuscript. MAI together with SAA supervised the biosorption study and helped in data interpretations while KOA prepared the biosorbents and carried out biosorption experiments. All authors read and approved the final manuscript.

\section{Authors' information}

Dr. Adeogun Abideen is currently a Senior Lecturer in the Chemistry Department at Federal University of Agriculture, Abeokuta Nigeria. He bagged his PhD in Biophysical Chemistry in 1999 at the University of Ibadan, Nigeria. Dr. Idowu Mopelola is an associate Professor with specialization in surface and photochemistry in the Chemistry Department at Federal University of Agriculture, Abeokuta Nigeria. She obtained her PhD in 2008 at Rhodes University, Grahamstown, South Africa. Dr. Ahmed Sikiru specialized in Computational Chemistry, he is currently a senior lecturer at Kwara State University, Ilorin. Mr
Akiode Kayode is currently a PhD student in the Department of Chemistry, Federal University of Agriculture, Abeokuta Nigeria.

\section{Author details}

${ }^{1}$ Chemistry Department, Federal University of Agriculture, Abeokuta, Nigeria.

${ }^{2}$ Chemistry Department, Kwara State University Ilorin, Ilorin, Nigeria.

\section{Acknowledgements}

The financial support in the form of grants from CSIR, for twelve months TWAS-CSIR Postdoctoral Fellowship, FR number: 3240275035 , awarded to Abideen Idowu Adeogun that enables part of this work to be carried out is highly acknowledge. Also he is thankful to the authority of the Federal University of Agriculture, Abeokuta, Nigeria for granting the study leave to honour the fellowship.

\section{Competing interests}

The authors declare that they have no competing interests.

Received: 9 November 2015 Accepted: 29 February 2016

Published online: 12 February 2016 


\section{References}

Adeogun Al, Balakrishnan RB (2015a) One-step synthesized calcium phosphate based material for the removal of Alizarin $\mathrm{S}$ dye from aqueous solutions: isothermal, kinetics and thermodynamics studies. J Appl Nanosci 5(2):1-13. doi:10.1007/s13204-015-0484-9

Adeogun Al, Balakrishnan RB (2015b) Kinetics, isothermal and thermodynamics studies of electrocoagulation removal of basic dye rhodamine $B$ from aqueous solution using steel electrodes. Appl Water Sci 5(18):1-13. doi:10.1007/s13201-015-0337-4

Adeogun Al, Andrew AE, Idowu MA, Ahmed SA, Kareem SO (2012) Biosorption of $\mathrm{Cr}(\mathrm{VI})$ ion from aqueous solution by Maize Husk: isothermal, kinetics and thermodynamic study. J.Chem.Soc.Pak 34(6)

Ahmad MA, Puad NAA, Bello OS (2014) Kinetic, equilibrium and thermodynamic studies of synthetic dye removal using pomegranate peel activated carbon prepared by microwave-induced $\mathrm{KOH}$ activation. Water Resour Ind 6:18-35

Ajmal M, Khan H, Ahmad S, Ahmad A (1998) Role of sawdust in the removal of copper (II) from industrial wastes. Water Res 32:3085-3091

Antunes WM, Luna AS, Henriques CA, da Costa ACA (2003) An evaluation of copper biosorption by a brown seaweed under optimized conditions. Electron J Biotechnol 6(3):174-184

Aydin H, Bulut Y, Yerlikaya C (2008) Removal of copper(II) from aqueous solution by adsoption onto low-cost adsorbents. J Environ Manage 87(1):37-45

Bajpai SK, Jain A (2010) Removal of copper(II) from aqueous solution using spent tea leaves (STL) as a potential sorbent. Water SA 36(3):221-228

Brewer GJ (2007) Iron and copper toxicity in diseases of aging, particularly atherosclerosis and Alzheimer's disease". Exp Biol Med 232:323-335

Brewer GJ (2010) Copper toxicity in the general population Clin. Neurophysiol 121:459-460

Dubinin MM, Radushkevich LV (1947) Equation of the characteristic curve of activated charcoal, Proceedings of the Academy of Sciences, Physical Chemistry Section, U.S.S.R. 55, 331-333

Faller P (2009) Copper and zinc binding to amyloid-beta: coordination, dynamics, aggregation, reactivity and metal-ion transfer. ChemBioChem 10:2837-2845

Fernandes JC, Henriques FS (1991) Biochemical, physiological and structural effects of excess copper in plants. Bot Rev 57:246-273

Foo KY, Hameed BH (2010) Insights into the modeling of adsorption isotherm systems. Chem Eng J 156(1):2-10

Freundlich HMF (1906) Over the adsorption in solution. J Phys Chem 57:385-471

Hajiboland R, Hasani BD (2007) Effect of Cu and Mn toxicity on chlorophyll fluorescence and gas exchange in rice and sunflower under different Light intensities. J Stress Physiol Biochem 3(1):4-17

Hansen HK, Arancibia F, Gutiérrez C (2010) Adsorption of copper onto agriculture waste materials. J Hazard Mater 180(1):442-448

Haureau C, Faller P (2009) A beta-mediated ROS production by Cu ions: structural insights, mechanisms and relevance to Alzheimer's disease. Biochimie 91:1212-1217

Hill TL (1949) Physical adsorption and the free volume model for liquids. J Chem Phys 17(6):590

Ho YS, McKay G (1998) Kinetic models for the sorption of dye from aqueous solution by wood. Process Saf Environ Prot 76(2):183-191

Ho YS, McKay G (1999) Pseudo-second order model for sorption processes. Process Biochem 34(5):451-465

Ho YS, Ofomaja AE (2006) Kinetic studies of copper ion adsorption on palm kernel fibre. J Hazard Mater 137(3):1796-1802

Jafar AA, Shajudha AB (2012) Adsorption of copper from aqueous solution using low- cost adsorbent. Arch Appl Sci Res 4(3):1532-1539
Kakavandi B, Kalantary RR, Jafari AJ, Nasseri S, Ameri A, Esrafili A, Azari A (2015) $\mathrm{Pb}$ (II) adsorption onto a magnetic composite of activated carbon and superparamagnetic $\mathrm{Fe}_{3} \mathrm{O}_{4}$ nanoparticles: experimental and modeling study. CLEAN Soil Air Water 43(8):1157-1166

Kalavathy MH, Miranda LR (2010) Comparison of copper adsorption from aqueous solution using modified and unmodified Hevea brasiliensis saw dust. Desalination 255(1):165-174

Khormaei M, Nasernejad B, Edrisi M, Eslamzadeh T (2007) Copper biosorption from aqueous solutions by sour orange residue. J Hazard Mater 149(2):269-274

Langmuir I (1918) The adsorption of gases on plane surfaces of glass, mica and platinum. J Am Chem Soc 40:1361-1403

Lin J, Zhan Y, Zhu Z (2011) Adsorption characteristics of copper (II) ions from aqueous solution onto humic acid-immobilized surfactant-modified zeolite. Colloids Surf A Physicochem Eng Asp 384(1):9-16

Munagapati VS, Yarramuthi V, Nadavala SK, Alla SR, Abburi K (2010) Biosorption of $\mathrm{Cu}^{2+}, \mathrm{Cd}(\mathrm{II})$ and $\mathrm{Pb}(\mathrm{II})$ by Acacia leucocephala bark powder: kinetics, equilibrium and thermodynamics. Chem Eng J 157:357-365

Ofomaja AE (2010) Equilibrium studies of copper ion adsorption onto palm kernel fibre. J Environ Manage 91(7):1491-1499

Okafor PC, Okon PU, Daniel EF, Ebenso EE (2012) Adsorption capacity of coconut (Cocos Nucifera L.) shell for lead, copper, cadmium and arsenic from aqueous solutions. Int J Electrochem Sci 7:12354-12369

Oyedeji OA, Osinfade GB (2010) Removal of copper (II), iron (II) and lead (II) ions from mono-omponent simulated water effluent by adsorption on coconut husk. Afri J Environ Sci Technol 4(6):382-387

Park D, Yun YS, Park JM (2005) Studies on hexavalent chromium biosorption by chemically-treated biomass of Ecklonia sp.. Chemosphere 60:1356-1364

Putra WP, Kamari A, Yusoff SNM, Ishak CF, Mohamed A, Hashim N, Isa I (2014) Biosorption of $\mathrm{Cu}(\mathrm{II}), \mathrm{Pb}$ (II) and $\mathrm{Zn}$ (II) ions from aqueous solutions using selected waste materials: adsorption and characterisation studies. J Encapsul Adsorpt Sci 2014(4):25-35

Redlich O, Peterson DL (1959) A useful adsorption isotherm. J Phys Chem 63:1024-1026

Sips R (1948) Combined form of Langmuir and Freundlich equations. J Chem Phys 16:490-495

Sun JX, Sun XF, Sun RC, Fowler P, Baird MS (2003) Inhomogeneities in the chemical structure of sugarcane bagasse lignin. J Agric Food Chem 51:6719-6725

Tempkin MI, Pyzhev V (1940) Kinetics of ammonia synthesis on promoted iron catalyst. Acta Physica Chimca USSR 12(1940):327-356

Tóth J (1995) Uniform interpretation of gas/solid adsorption. Adv Colloid Interface Sci 55:1-239

Veli S, Alyüz B (2007) Adsorption of copper and zinc from aqueous solutions by using natural clay. J Hazard Mater 149(1):226-233

Vukovic GD, Marinkovic AD, Skapin SD, Ristic MD, Aleksic R, Peric-Grujic AA, Uskokovic P (2011) Removal of lead from water by amino modified multiwalled carbon nanotubes. Chem Eng J 173(3):855-865

Zeldowitsch J (1934) Über den mechanismus der katalytischen oxydation von $\mathrm{CO}$ an $\mathrm{MnO}_{2}$. Acta Physicochem URSS 1:364-449

\section{Submit your manuscript to a SpringerOpen ${ }^{\odot}$ journal and benefit from:}

- Convenient online submission

- Rigorous peer review

- Immediate publication on acceptance

- Open access: articles freely available online

- High visibility within the field

- Retaining the copyright to your article

Submit your next manuscript at $>$ springeropen.com 